\title{
Magnitude and associated factors of anemia among pregnant women in Dera District: a cross-sectional study in northwest Ethiopia
}

Terefe Derso $^{1 *}$, Zelalem Abera ${ }^{2}$ and Amare Tariku ${ }^{1}$

\begin{abstract}
Background: Anemia is associated with adverse health and socio-economic consequences among pregnant women. Particularly, severe anemia increases the risk of maternal mortality by $20 \%$. However, literatures are scarce in the northwest Ethiopia. Therefore, this study aimed to determine the magnitude and associated factors of anemia among pregnant women attending antenatal care in Dera District, South Gondar Zone, northwest Ethiopia.

Methods: A facility-based cross-sectional study was conducted in Dera District health centers from June 27 to September 2, 2015. Capillary blood samples were taken from 348 pregnant women. The raw measured values of hemoglobin were obtained using the portable $\mathrm{Hb} 301$ instrument and adjusted for altitude. Besides, nutritional status of the women was assessed by the mid upper arm circumference (MUAC) taken on non-dominant upper limb, mostly of the left hand. Socio-demographic factors, obstetric history, environmental related factors and dietary intake were collected by interviewing the pregnant women. A multivariate logistic regression analysis was employed to identify factors associated with anemia. Adjusted odds ratio (AOR) with corresponding 95\% confidence interval (Cl) was computed to show the strength of association. In multivariable analysis, a $P$ value of $<0.05$ was used to declare statistical significance.
\end{abstract}

Results: The overall prevalence of anemia among pregnant women was $30.5 \%$ [95\% $\mathrm{Cl} 21.0,40.0]$. The result of multivariable analysis revealed that the likelihood of anemia was higher among pregnant women living in rural areas $[\mathrm{AOR}=3.03,95 \% \mathrm{Cl} 1.17,7.82]$, had no latrine $[\mathrm{AOR}=4.75,95 \% \mathrm{Cl} 1.15,16.60]$, low monthly income: <Eth. Birr 1200 (US dollar 52.22) $[\mathrm{AOR}=2.56,95 \% \mathrm{Cl} 1.17,5.60]$, five or above parity $[\mathrm{AOR}=4.17 ; 95 \% \mathrm{Cl} 1.62,10.69], \mathrm{MUAC}<23 \mathrm{~cm}$ $[A O R=4.97 ; 95 \% \mathrm{Cl} 2.61,9.43]$ and did not prenatal take iron supplementation $[\mathrm{AOR}=5.63 ; 95 \% 2.21,14.32]$.

Conclusion: So far in the district, the magnitude of anemia existed as a moderate public health concern. Thus, improved socio-economic status, latrine and maternal iron supplementation coverage are essential to mitigate the high burden of anemia. In addition, nutritional counseling and education on the consumption of extra meals and iron-rich foods should be intensified.

Keywords: Anemia, Pregnant women, Iron supplementation, Northwest Ethiopia

\footnotetext{
*Correspondence: dersotere@gmail.com

1 Department of Human Nutrition, Institute of Public Health, College

of Medicine and Health Sciences, University of Gondar, P.O.Box:196,

Gondar, Ethiopia

Full list of author information is available at the end of the article
} 


\section{Background}

Anemia is a serious public health problem among pregnant women in developing countries [1, 2]. About 95.7\% of the global burden of prenatal anemia is found in developing countries [3]. Nearly half $(46.3 \%)$ of the pregnant women in Africa are anemic [4], likewise two-third $(62.7 \%)$ are suffering from the problem in Ethiopia [2].

The prenatal anemia is associated with adverse health and socio-economic consequences [2]. Impaired physical strength and increased risks of maternal morbidity are common among anemic pregnant women. Particularly, the risk of mortality raises by $20 \%$, in case of severe anemia [5-9]. Also maternal anemia affects the growing fetus and the newborn. The higher odds of fetal anemia, preterm delivery, low birth weight (LBW), intrauterine fetal growth restriction and perinatal mortality are reported among anemic pregnant mothers [7-9].

Because of increased volume of water in the blood, resulting in hemo-dilution and rapid fetal growth pregnant women are highly vulnerable to anemia [10-12]. Cognizant of this condition the World Health Organization (WHO) recommends universal iron-folate supplementation for pregnant women [13].

Based on the previous findings, prenatal anemia is associated with maternal co-existing nutrient deficiencies, obstetric morbidities, socio-demographic and economic characteristics. Accordingly, deficiency of some micronutrients (vitamin $\mathrm{C}$, vitamin $\mathrm{B} 12$ and vitamin $\mathrm{A}$ ) which impairs the absorption and bioavailability of iron [14-16], under-nutrition (MUAC < $23 \mathrm{~cm}$ ) [17], low meal frequency ( $<3$ times per day) [18] and not taking ironfolate supplementation [19] are related with increased odds of maternal anemia. History of obstetric morbidities, such as intestinal parasitic infestations and recurrent malarial attack are correlated with prenatal anemia [16, 20-22]. Also high risk of anemia is reported among mothers with advanced gestational age [23], high parity [24] and gravidity [25]. Rural residence [21], illiteracy [26], large family size [27] and poor economic status [28] are found the socio-economic determinants of anemia.

Ethiopia recognizes the maternal anemia as a severe public health concern for decades, consequently national nutrition program and the micronutrient deficiency prevention and control strategy has been implemented in the country $[29,30]$. Universal iron-folate supplementation is currently given for all pregnant women attending antenatal care (ANC) in Ethiopia [29]. However, only $34 \%$ of mothers are found to have at least one antenatal care which makes implementation of universal ironfolate supplementation more challenging. Besides, only $17 \%$ of mothers took the supplementation during pregnancy while less than $1 \%$ of them took for full schedule (90 days) [31]. Nevertheless, anemia is one of the rampant nutritional problem in Ethiopia, literatures are scarce. Therefore, this study aimed to identify the magnitude and associated factors of anemia among pregnant women attending ANC in Dera District, South Gondar Zone, northwest Ethiopia.

\section{Methods}

\section{Study setting and design}

A facility-based cross-sectional study was conducted in Dera District health centers from June 27 to September 2 , 2015. The district is located in South Gondar administrative zone, $602 \mathrm{~km}$ from Addis Ababa, the capital of Ethiopia. The altitude of the district ranges from 1500 to $2500 \mathrm{~m}$ above sea level. A total of 282,775 populations reside in the district. A total of ten health centers are found in Dera District.

\section{Study participants and sampling procedure}

All pregnant women who attended ANC in Dera District health centers were eligible for the study. To estimate the magnitude of anemia among pregnant women, sample size was calculated using single proportion formula by considering the following assumptions; $16.6 \%$ as the prevalence of anemia among pregnant women in Gondar District [32], 95\% level of confidence, 5\% margin of error, $10 \%$ non-response rate and a design effect of 1.5 . Thus, the final sample size of 351 was obtained. Regarding the sampling procedure, initially a lottery method was employed to select three health centers out of ten health centers. After estimating the average number of pregnant women attending ANC in the past 2 months using the registration log-book, the proportional allocation was used to calculate the total number of mothers selected from each health center. As a result, 124, 115 and 109 pregnant women were selected using a systematic sampling technique from Ambesame, Aribgebya and Hamusit health centers, respectively.

\section{Data collection tools and procedure}

A structured and pretested questionnaire was used to obtain socio-demographic information, obstetric history, environmental and dietary intake related characteristics of the study participants. The questionnaire was originally prepared in English and then translated to Amharic to local language and back to English in order to obtain content validity. Three BSc clinical nurses and three laboratory technologists were participated as data collector while three senior public health officers were involved as a supervisor. Two days training was given to data collectors and supervisors regarding the objective of the study, confidentiality of information, and techniques of interview. Pre-test was done among 5\% of the total sample in Woreta health center. During pre-test the questionnaire 
was assessed for its clarity, wording and the optimal time for completing the interview. Modifications were done based on the result. The investigators and the supervisors made regular supervision.

\section{Measurement of hemoglobin concentration and mid upper} arm circumference (MUAC)

Capillary blood samples were taken. The raw measured values of hemoglobin were obtained using the portable Hb301 instrument and adjusted for altitude [12, $31,33]$. The outcome variable, anemia was defined as proportion of pregnant women whose blood hemoglobin concentration of less than $11 \mathrm{~g} / \mathrm{dl}$. Also anemia was classified into three categories as mild, moderate and severe anemia when the mother's hemoglobin level was $10-10.9,7-9.9 \mathrm{~g} / \mathrm{dl}$ and less than $7 \mathrm{~g} / \mathrm{dl}$, respectively [34]. In addition, the mid upper arm circumference (MUAC) was measured on the non-dominant hand, mostly of the left hand. The result was interpreted according to the WHO and Food and Nutrition Technical Assistance Project (FANTA) recommendation, in which a mother was defined as undernourished if her MUAC was less than $23 \mathrm{~cm}$, whereas she was well nourished if the MUAC was greater than or equal to $23 \mathrm{~cm}$ $[35,36]$.

\section{Data analysis}

Data were checked, coded and entered into Epi-info software version 3.5.3 and exported to Statistical Package for Social Science (SPSS) version 20 for analysis. The bivariate and multivariate analysis were done. All variables with a $P$ value of less than 0.2 in bivariate analysis were entered to multivariate analysis to control the possible effect of confounders. Multi-co-linearity was checked for household income and latrine availability, and the result showed that the two independent variables had no significant co-linearity. Both crude odds ratio (COR) and adjusted odds ratio (AOR) with a $95 \%$ confidence interval (CI) were estimated to show the strength of association. In multivariate analysis, variables with a $P$ value of $\leq 0.05$ were considered as statistical significant.

\section{Results}

\section{Socio-demographic and economic characteristics}

A total of 348 pregnant women were included in the study with the response rate of $99.1 \%$. The mean ( \pm standard deviation, SD) age of the pregnant women was 26.31 $( \pm 5.93)$ years. Almost all $(98.9 \%)$ of the pregnant women were married. Nearly half (48.9\%) of the pregnant women did not wear shoe. Besides, more than three-fourth (79, 76.7 and $76.4 \%$, respectively) of the pregnant women were farmer, lives in rural areas and had no formal education (Table 1).
Table 1 Socio-demographic and economic characteristics of pregnant women attending antenatal care in Dera District health facilities, Ethiopia, 2015

\begin{tabular}{|c|c|c|}
\hline Variables & Frequency $(n=348)$ & Percent \\
\hline \multicolumn{3}{|l|}{ Age in years } \\
\hline $15-19$ & 37 & 10.6 \\
\hline $20-29$ & 200 & 57.5 \\
\hline $30-39$ & 104 & 29.9 \\
\hline$\geq 40$ & 7 & 2 \\
\hline Mean $( \pm S D)$ age & $26.31( \pm 5.93)$ & \\
\hline \multicolumn{3}{|l|}{ Residence } \\
\hline Rural & 267 & 76.7 \\
\hline Urban & 81 & 23.3 \\
\hline \multicolumn{3}{|l|}{ Occupation } \\
\hline Farmer & 275 & 79 \\
\hline Merchant & 40 & 11.5 \\
\hline Others $^{a}$ & 33 & 9.5 \\
\hline \multicolumn{3}{|l|}{ Religion } \\
\hline Christian orthodox & 345 & 98.6 \\
\hline Muslim & 5 & 1.4 \\
\hline \multicolumn{3}{|l|}{ Marital status } \\
\hline Currently married & 344 & 98.9 \\
\hline Currently unmarried $^{b}$ & 4 & 1.1 \\
\hline \multicolumn{3}{|l|}{ Educational status } \\
\hline No formal education & 266 & 76.4 \\
\hline Primary school & 50 & 14.4 \\
\hline Secondary school & 22 & 6.3 \\
\hline Above secondary school & 10 & 2.9 \\
\hline \multicolumn{3}{|l|}{ Household monthly income } \\
\hline$\leq$ Eth. Birr 500 (US dollar 21.78) & 57 & 16.4 \\
\hline $\begin{array}{l}\text { Eth. Birr 501-850 (US dollar } \\
\text { 21.8-36.99) }\end{array}$ & 55 & 15.8 \\
\hline $\begin{array}{l}\text { Eth. Birr 851-1200 (US dollar } \\
\text { 37.03-52.22) }\end{array}$ & 139 & 39.9 \\
\hline >Eth. Birr 1200 (US dollar 52.22) & 97 & 27.9 \\
\hline \multicolumn{3}{|l|}{ Source of drinking water } \\
\hline Tap water & 140 & 40.2 \\
\hline Protected spring water & 103 & 29.6 \\
\hline Unprotected spring water & 11 & 3.2 \\
\hline River water & 94 & 27 \\
\hline \multicolumn{3}{|l|}{ Wearing of shoes consistently } \\
\hline Yes & 178 & 51.1 \\
\hline No & 170 & 48.9 \\
\hline
\end{tabular}

ETB Ethiopian Birr

a Civil servant and housewife

b Divorced

\section{Obstetric and other medical related characteristics}

About one-fourth $(25.9 \%)$ of the participants had four and above parities. Majority (46.3\%) of the pregnant women were found in the second trimester (gestational age between 12 and 28 weeks) of pregnancy. Besides, 73\% 
of the pregnant women had history of multi-gravidity. Majority, 325 (93.4\%) of the study participants reported that they utilized mosquito bed net (Table 2).

\section{Nutrition related characteristics}

More than one-third (35.5\%) of the pregnant women were undernourished (MUAC $<23 \mathrm{~cm}$ ). Besides, only $18.1 \%$ of pregnant women had a meal frequency of four and above in the previous 24-h preceding the date of survey. Two-third (67\%) of pregnant women did not consume animal products, such as red meat, organ meat and egg at least once per week (Table 3).

\section{Prevalence of anemia}

The overall prevalence of anemia among pregnant women was $30.5 \%$ [ $95 \%$ CI 21.0, 40.0], of which, one out of ten $(10.1 \%)$ of the women were moderately anemic

Table 2 Obstetric and medical history of pregnant women attending antenatal care in Dera District health facilities, Ethiopia, 2015

\begin{tabular}{|c|c|c|}
\hline Variables & Frequency & Percent \\
\hline \multicolumn{3}{|l|}{ Parity } \\
\hline No & 88 & 25.3 \\
\hline One & 62 & 17.8 \\
\hline $2-3$ & 108 & 31 \\
\hline 4 and above & 90 & 25.9 \\
\hline \multicolumn{3}{|c|}{ Space between pregnancy } \\
\hline$<2$ years & 9 & 2.6 \\
\hline$\geq 2$ years & 251 & 72.1 \\
\hline No child & 88 & 25.3 \\
\hline \multicolumn{3}{|c|}{ Gestational age in weeks } \\
\hline$<12$ & 53 & 15.2 \\
\hline $12-28$ & 161 & 46.3 \\
\hline$>28$ & 134 & 38.5 \\
\hline \multicolumn{3}{|c|}{ Number of gravidity } \\
\hline Primigravida & 94 & 27 \\
\hline Multigravida & 254 & 73 \\
\hline \multicolumn{3}{|c|}{ History if vaginal bleeding } \\
\hline Yes & 21 & 6 \\
\hline No & 327 & 94 \\
\hline \multicolumn{3}{|c|}{ History of infection with intestinal parasite } \\
\hline Yes & 78 & 22.4 \\
\hline No & 270 & 77.6 \\
\hline \multicolumn{3}{|c|}{ History of malaria infection } \\
\hline Yes & 82 & 23.6 \\
\hline No & 266 & 76.4 \\
\hline \multicolumn{3}{|c|}{ Current utilization of ITN } \\
\hline Yes & 325 & 93.4 \\
\hline No & 23 & 6.6 \\
\hline
\end{tabular}

ITN insecticide treated net
Table 3 Nutrition related characteristics of pregnant women attending antenatal care in Dera District health facilities, Ethiopia, 2015

\begin{tabular}{lcc}
\hline Variables & Frequency & Percent \\
\hline MUAC & 125 & \\
Undernourished (MUAC $<23 \mathrm{~cm})$ & 223 & 64.8 \\
Normal (MUAC $\geq 23 \mathrm{~cm})$ & & \\
Meal frequency in the previous 24 h & 86 & 24.7 \\
Twice & 199 & 57.2 \\
Three times & 63 & 18.1 \\
Four and above times & 303 & 87.1 \\
History of iron supplementation for the current pregnancy & \\
Yes & 45 & 12.9 \\
No & 156 & 44.8 \\
Eating vegetables food groups at least once per week & \\
Yes & 192 & 55.2 \\
No & 115 & 67 \\
Eating animal source food at least once per week & \\
Yes & 233 & 33 \\
No &
\end{tabular}

(Fig. 1). The mean hemoglobin level $( \pm \mathrm{SD})$ was 12.07 $( \pm 2.24) \mathrm{g} / \mathrm{dl}$.

\section{Factors associated with anemia}

In bivariate analysis residence, parity, household monthly income, availability of latrine, frequency of meal per day, iron supplementation, history of intestine parasite infestation, eating animal source of food at least once per week, history of malaria infection, and nutritional status were found with a P value of less than 0.2. On the other hand, the result of multivariate analysis showed that residence, parity, latrine availability, household monthly income, iron supplementation and nutritional status were significantly and independently associated with anemia. Consequently, the odds of anemia were higher among pregnant women living in rural areas $[\mathrm{AOR}=3.03,95 \% \mathrm{CI} 1.17,7.82]$ and in households without latrine $[\mathrm{AOR}=4.75,95 \% \mathrm{CI} 1.15,16.60]$. Increased odds of anemia were observed among pregnant women with $\mathrm{MUAC}<23 \mathrm{~cm}$ [AOR = 4.97; 95\% CI 2.61, 9.43] and who did not take iron supplementation $[\mathrm{AOR}=5.63$; 95\% 2.21, 14.32]. Besides, the likelihoods of anemia was higher among pregnant women who were in the household with an income less than Eth. Birr 1200 (US dollar $52.22)[\mathrm{AOR}=2.56$, $\mathrm{CI}(1.17,5.60)]$ and five or more parity $[\mathrm{AOR}=4.17 ; 95 \% \mathrm{CI} 1.62,10.69]$ (Table 4 ).

\section{Discussion}

This study revealed that, the overall magnitude of anemia among pregnant women was $30.5 \%$. The result was similar with the former findings in Ethiopia (21.6-36.6\%) 


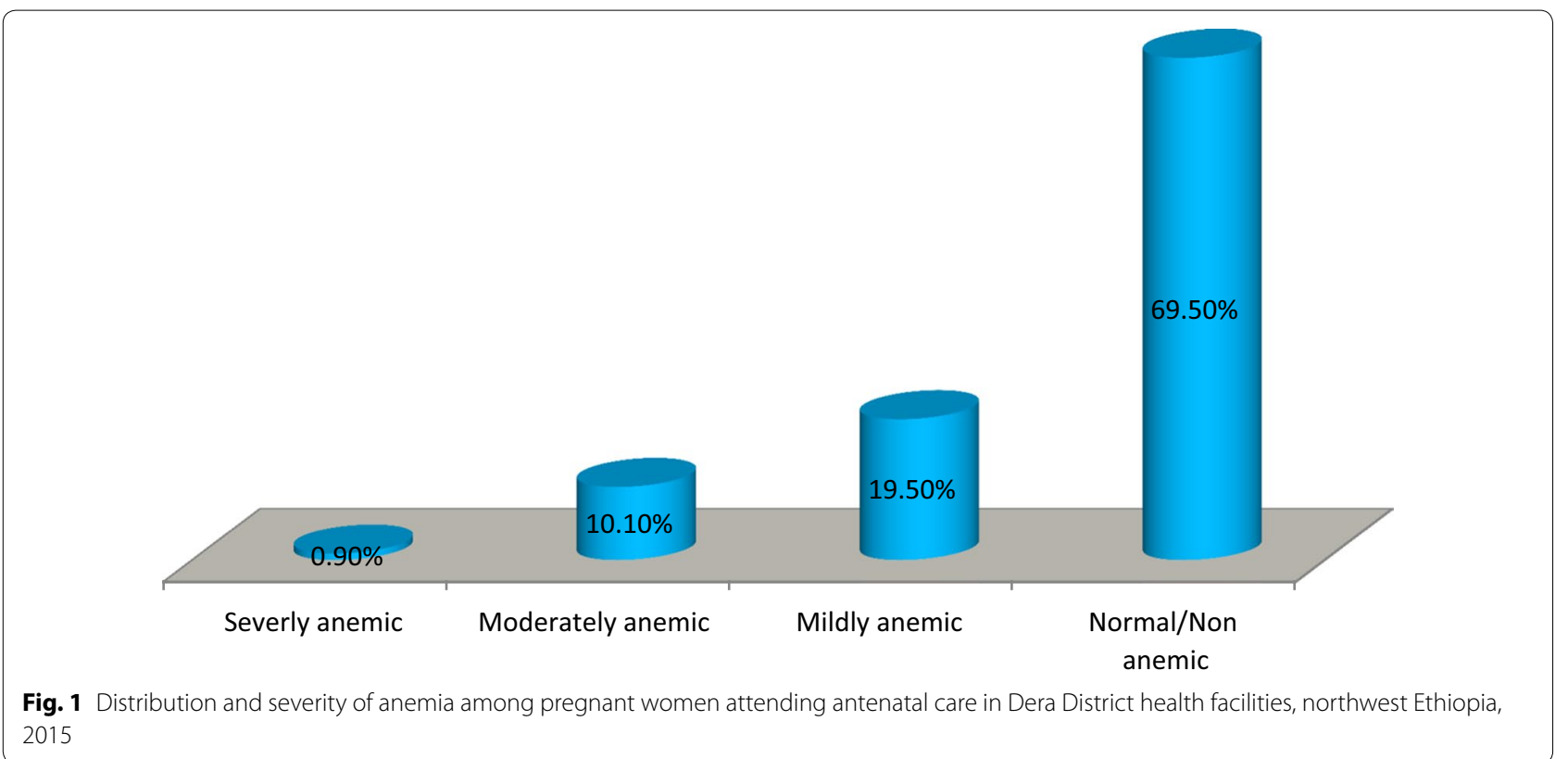

[17, 21, 31, 37] and northern Nigeria (30\%) [38]. However, this prevalence was higher than other reports in Ethiopia, such as Gondar District (16.6\%) [32], Awaassa District (15\%) [39] and Mekelle District (19.7\%) [18] and Iran $(13.6 \%)$ [40]. The observed discrepancy might be due to rural residence of women $(76.7 \%)$ in the current study area compared to the latter study settings. Pregnant women living in the rural areas were more likely to be affected with community belief towards poor feeding practices, and had lower access to nutrition education and counseling [31]. Generally, unequal allocation of resources causes to inequalities in women health outcomes between rural and urban settlements. This implies that maternal undernutrition can decline by improving the quality of obstetric care during pregnancy [41].

The result of multivariable analysis also re-affirmed that, the likelihood of being anemic was 3.03 times higher among pregnant women living in rural areas compared to urban residents. Similar results were reported by other local studies $[17,21]$. Obviously, pregnant women residing in the rural areas have lack of information about extra nutrient intake during pregnancy and poor access to health care facilities which in-turn increases their vulnerability for anemia [31, 42].

The uncommon finding of this study illustrated a statistical significant association between maternal anemia and unavailability of latrine in the household. Open defecation especially, in high population density areas aggravates the contamination of the household environment $[43,44]$ and contribute to the risk of developing different intestinal parasitic diseases [45]. The intestinal parasitic infections are the common causes of malabsorption of nutrients, loss of appetite and increased blood loss thereby decreasing the hemoglobin concentration [4648]. In Africa two-third of pregnant women are at risk of hookworm related anemia [17, 49]. Therefore, improved hygiene and sanitation is a key to reduce risk of anemia, which mainly operates through reducing risk of recurrent intestinal parasitic infestations [41].

The odds of anemia were higher among pregnant women who did not take iron supplementation as compared to their counterparts. The result was supported by what was reported in Vietnam [18]. Though iron requirement increases during pregnancy, poor dietary intake of iron rich food is observed in this study and the 2011 Ethiopia Demographic and Health Survey report [31]. Even the cereal based monotonous dietary habit of the pregnant mothers and other population segments in developing countries including Ethiopia may not help them to ensure their extra requirement for iron [12]. Thus, supplementation of micronutrients, for instance iron and folic acid during pregnancy is not only used to prevent anemia, but it could also help to break the intergenerational cycle of low birth weight, stunting and future child and adult undernutrition [41].

The higher likelihood of anemia was noted among undernourished (MUAC $<23 \mathrm{~cm}$ ) pregnant women compared to the well-nourished pregnant women. This finding was consistent with the finding from Eastern Ethiopia [50]. This might be related to the negative effect of protein and other macronutrient deficiencies in impairing the bioavailability and storage of iron and other 
Table 4 Factors associated with anemia among pregnant women attending antenatal care in Dera District health facilities, Ethiopia, 2015

\begin{tabular}{|c|c|c|c|c|}
\hline \multirow[t]{2}{*}{ Variables } & \multicolumn{2}{|l|}{ Anemia } & \multirow{2}{*}{$\begin{array}{l}\text { Crude odds } \\
\text { ratio }(95 \% \mathrm{Cl})\end{array}$} & \multirow{2}{*}{$\begin{array}{l}\text { Adjusted odds } \\
\text { ratio }(95 \% \mathrm{Cl})\end{array}$} \\
\hline & Yes (\#) & No (\#) & & \\
\hline \multicolumn{5}{|l|}{ Residence } \\
\hline Rural & 78 & 189 & $4.36(1.96,8.08)$ & $3.03(1.17,7.82)^{*}$ \\
\hline Urban & 7 & 74 & 1.00 & 1.00 \\
\hline \multicolumn{5}{|l|}{ Parity } \\
\hline$<2$ children & 24 & 126 & 1.00 & 1.00 \\
\hline 2-4 children & 61 & 102 & $3.14(1.83,5.39)$ & $1.74(0.68,4.49)$ \\
\hline$>/=5$ children & 21 & 14 & $7.88(3.52,17.61)$ & $4.20(1.14,15.52)^{*}$ \\
\hline \multicolumn{5}{|l|}{ Household monthly income } \\
\hline$<$ Eth. Birr 2000 & 91 & 150 & $3.72(2.03,6.81)$ & $2.56(1.17,5.60)^{*}$ \\
\hline 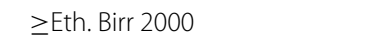 & 15 & 92 & 1.00 & 1.00 \\
\hline \multicolumn{5}{|l|}{ Availability of latrine } \\
\hline Yes & 94 & 238 & 1.00 & 1.00 \\
\hline No & 12 & 4 & $7.60(2.39,24.15)$ & $4.75(1.15,19.60)^{*}$ \\
\hline \multicolumn{5}{|l|}{ Gestational age in weeks } \\
\hline$<12$ & 17 & 36 & 1.00 & \\
\hline $12-28$ & 54 & 107 & $1.07(0.55,2.17)$ & \\
\hline$>28$ & 35 & 99 & $0.75(0.45,1.77)$ & \\
\hline \multicolumn{5}{|c|}{ Meal frequency in the previous $24 \mathrm{~h}$} \\
\hline 2 & 41 & 45 & $3.19(1.54,6.61)$ & \\
\hline 3 & 51 & 148 & $1.21(0.62,2.37)$ & \\
\hline 4 and above & 14 & 49 & 1.00 & \\
\hline \multicolumn{5}{|c|}{ Iron supplementation in the current pregnancy } \\
\hline Yes & 75 & 228 & 1.00 & 1.00 \\
\hline No & 31 & 14 & $6.73(3.40,13.32)$ & $5.63(2.21,14.32)^{*}$ \\
\hline \multicolumn{5}{|l|}{ Nutritional status } \\
\hline Normal/MUAC $\geq 23 \mathrm{~cm}$ & 38 & 185 & 1 & 1.00 \\
\hline Malnourished/MUAC < $23 \mathrm{~cm}$ & 68 & 57 & $5.80(3.54,9.53)$ & $4.97(2.61,9.43)^{*}$ \\
\hline
\end{tabular}

* $P$ value of $<0.05$

hematopoietic nutrients (folic acid and vitamin B12). As a result, most of the micronutrient deficiencies occurred with protein energy malnutrition, considering this fact the WHO and other local nutritional management guidelines recommend micronutrient supplementation as a routine intervention [51].

This study detected that, mothers with five and above history of parity were found with increased odds of anemia compared to those who had parity of less than two. The parallel result was indicated by the study in Mekelle District [18]. This can be explained by women having high parity is commonly observed with increased susceptibility to hemorrhage and maternal nutritional depletion syndrome [24]. In a healthy pregnancy, hormonal changes lead to an increase in plasma volume which causes reduction in hemoglobin level but does not drop below a certain level (e.g. $11.0 \mathrm{~g} / \mathrm{dl}$ ) [52]. Compared to the non-pregnant state, every pregnancy carries an increased risk of hemorrhage before, during, and after delivery and higher parity aggravates the risk of hemorrhage [24]. On the other hand, a woman with high parity has a large number of children [14], which implies high rate of sharing of available food and other family resources impairing the per capita food intake of pregnant women.

Finally, the odds of anemia were higher among women with household monthly income less than Eth. Birr 1200 compared to those from a household with monthly income of greater than Eth. Birr 1200. The similar findings were reported elsewhere $[28,32]$. It was evident that low household monthly income affects the household food purchasing power in kind and amount resulting in household food insecurity [41]. Consequently, people living in the poor households are found with impaired dietary intake and high risk of nutritional deficiencies [32].

This study showed the burden of anemia among the most vulnerable population groups, pregnant mothers, in 
Dera District where there is scarcity of literature. However, the study has some limitations, as an illustration the cross sectional nature of the study limits measuring the cause and effect relationship between the outcome and the potential determinants. There might be a recall and social desirability bias while measuring dietary information. Also, the serum iron, transferring and ferritin values were not measured and differences of geographic location and seasonality effect were not assessed. The study did not reveal the burdens of soil transmitted helminthes. Lastly, some of the confidence intervals are wide because of small number of cases in some two-by-two cells of variables.

\section{Conclusions}

Nearly one-third (30.5\%) of pregnant mothers were anemic in Dera District, indicating anemia as a moderate public health concern. Thus, improving socio-economic status, latrine and maternal iron supplementation coverage are essential to mitigate the burden of anemia. In addition to nutritional counseling and education on the consumption of extra meals and iron-rich foods should be intensified.

\begin{abstract}
Abbreviations
ANC: antenatal care; FANTA: Food and Nutrition Technical Assistance Project; MUAC: mid upper arm circumference; WHO: World Health Organization; AOR: adjusted odds ratio; COR: crude odds ratio; Cl: confidence interval; SD: standard deviation.
\end{abstract}

\section{Authors' contributions}

ZA conceived the study, developed the tool, coordinated data collection, and carried out the statistical analysis and drafted the manuscript. TD participated in the design of the study, developed the tool, and coordinated data collection and carried out the statistical analysis and drafted the manuscript. AT participated in the statistical analysis and drafted the manuscript. All authors read and approved the final manuscript.

\section{Author details}

${ }^{1}$ Department of Human Nutrition, Institute of Public Health, College of Medicine and Health Sciences, University of Gondar, P.O.Box:196, Gondar, Ethiopia. 2 John Snow Integrated Family Health Program, Ethiopia, P.O.Box:1841, Bahirdar, Ethiopia.

\section{Acknowledgements}

We would like to thank mothers for their willingness to participate in the study. Our appreciation will also go to the Dera District Health Office for material support.

\section{Competing interests}

The authors declare that they have no competing interests.

\section{Availability of data and materials}

Data will be made available upon request from the corresponding authors.

\section{Consent to publish}

Not applicable.

\section{Ethics approval and consent to participate}

Bahir Dar University, Institute of Technology, School of Chemical and Food was approved the study protocol and then ethical clearance was obtained from research and publication committee of Bahir Dar University. After explanation about the whole purpose of the study, further permission was obtained from Amhara National Regional State Health Bureau, South Gondar Zone health department as well as Dera District health office. Verbal consent was obtained from study participants after a detailed discussion and explanations about the purpose, benefit and the possible risks of the study. Also parents' or legal guardians' consent was obtained for study participants aged 17 or younger. The confidentiality of information was guaranteed by using code numbers rather than personal identifiers and by keeping the data locked. Participants were told to decline at any time if they feel uncomfortable, even after the interview has started.

\section{Funding}

The authors received no specific funding for this work.

\section{Publisher's Note}

Springer Nature remains neutral with regard to jurisdictional claims in published maps and institutional affiliations.

Received: 14 June 2016 Accepted: 26 July 2017

Published online: 01 August 2017

\section{References}

1. Kozuma S. Approaches to anemia in pregnancy. JMAJ. 2009;52(4):214-8.

2. McLean E, Cogswell M, Egli I, Wojdyla D, De Benoist B. Worldwide prevalence of anaemia, WHO vitamin and mineral nutrition information system, 1993-2005. Public Health Nutr. 2009;12(04):444-54.

3. Van Den Broek N. Anaemia and micronutrient deficiencies: reducing maternal death and disability during pregnancy. Br Med Bull. 2003;67(1):149-60

4. World Health Organization. The global prevalence of anaemia in 2011. Geneva: World Health Organization; 2015.

5. Allen LH. Anemia and iron deficiency: effects on pregnancy outcome. Am J Clin Nutr. 2000;71(5):1280s-4s.

6. World Health Organization. Vitamin and mineral nutrition information system evidence and programme guidance unit nutrition for health and development. Geneva: World Health Organization; 2015.

7. Haggaz AD, Radi EA, Adam I. Anaemia and low birthweight in western Sudan. Trans R Soc Trop Med Hyg. 2010;104(3):234-6.

8. Kidanto HL, Mogren I, Lindmark G, Massawe S, Nystrom L. Risks for preterm delivery and low birth weight are independently increased by severity of maternal anaemia. S Afr Med J. 2009;99(2):98-102.

9. World Health Organization. Iron deficiency anaemia: assessment, prevention and control: a guide for programme managers. Geneva: World Health Organization; 2001.

10. Yip R. Significance of an abnormally low or high hemoglobin concentration during pregnancy: special consideration of iron nutrition. Am J Clin Nutr. 2000;72(1):272s-9s.

11. Bothwell TH. Iron requirements in pregnancy and strategies to meet them. Am J Clin Nutr. 2000;72(1):257s-64s

12. World Health Organization. Haemoglobin concentrations for the diagnosis of anaemia and assessment of severity. Geneva: World Health Organization; 2011.

13. World health Organization. WHO recommendations on antenatal care for a positive pregnancy experience. Geneva: World Health Organization; 2016.

14. Allen LH. Multiple micronutrients in pregnancy and lactation: an overview. Am J Clin Nutr. 2005;81:S1206-12.

15. Haidar J. Prevalence of anaemia, deficiencies of iron and folic acid and their determinants in Ethiopian women. J Health Popul Nutr. 2010;28(4):359-68.

16. Uneke CJ, Duhlinska DD, Igbinedion EB. Prevalence and public-health significance of HIV infection and anaemia among pregnant women attending antenatal clinics in south-eastern Nigeria. J Health Popul Nutr. 2007;25(3):328-35.

17. Kefiyalew F, Zemene E, Asres Y, Gedefaw L. Anemia among pregnant women in Southeast Ethiopia: prevalence, severity and associated risk factors. BMC Res Notes. 2014;7(1):1. 
18. Abriha A, Yesuf ME, Wassie MM. Prevalence and associated factors of anemia among pregnant women of Mekelle town: a cross sectional study. BMC Res Notes. 2014;7(1):1.

19. Aikawa R, Khan NC, Sasaki S, Binns CW. Risk factors for iron-deficiency anaemia among pregnant women living in rural Vietnam. Public Health Nutr. 2006;9(04):443-8.

20. UNICEF, World Health Organization. Improving nutrition outcomes with better water, sanitation and hygiene: practical solutions for policies and programmes. Geneva: World Health Organization; 2015.

21. Alem M, Enawgaw B, Gelaw A, Kenaw T, Seid M, Olkeba Y. Prevalence of anemia and associated risk factors among pregnant women attending antenatal care in Azezo Health Center Gondar town, Northwest Ethiopia. J Interdiscip Histopathol. 2013;1 (3):137-44.

22. Getachew M, Yewhalaw D, Tafess K, Getachew Y, Zeynudin A. Anaemia and associated risk factors among pregnant women in Gilgel Gibe dam area, Southwest Ethiopia. Parasites Vectors. 2012;5(1):1.

23. Makhoul Z, Taren D, Duncan B, Pandey P, Thomson C, Winzerling J, Muramoto M, Shrestha R. Risk factors associated with anemia, iron deficiency and iron deficiency anemia in rural Nepali pregnant women. Southeast Asian J Trop Med Public Health. 2012;43(3):735.

24. Al-Farsi YM, Brooks DR, Werler MM, Cabral HJ, Al-Shafei MA, Wallenburg $\mathrm{HC}$. Effect of high parity on occurrence of anemia in pregnancy: a cohort study. BMC Pregnancy Childbirth. 2011;11(1):1.

25. Viveki RG, Halappanavar AB, Viveki PR, Halki SB, Maled VS, Deshpande PS. Prevalence of anaemia and its epidemiological determinants in pregnant women. Al Ameen J Med Sci. 2012:5(3):216-23.

26. Bisoi S, Haldar D, Majumdar TK, Bhattacharya N, Sarkar GN, Ray SK. Correlates of anaemia among pregnant women in a rural area of West Bengal. J Fam Welf. 2011:57(1):72-8.

27. Haidar JA, Pobocik RS. Iron deficiency anemia is not a rare problem among women of reproductive ages in Ethiopia: a community based cross sectional study. BMC Hematol. 2009;9(1):1.

28. Salhan S, Tripathi V, Singh R, Gaikwad HS. Evaluation of hematological parameters in partial exchange and packed cell transfusion in treatment of severe anemia in pregnancy. Anemia. 2012;2012:1-7.

29. Federal Ministry of Health, Family Health Department Ethiopia. National guideline for control and prevention of micronutrient deficiencies. Addis Ababa: Federal Ministry of Health, Family Health Department Ethiopia; 2004.

30. Government of the Federal Democratic and Republic of Ethiopia. National Nutrition Program 2013-2015.

31. Central Statistical Agency [Ethiopia] and ICF International. Ethiopia Demographic and Health Survey 2011. Central Statistical Agency Addis Ababa and ICF International Calverton, Maryland, USA: 2012.

32. Melku M, Addis Z, Alem M, Enawgaw B. Prevalence and predictors of maternal anemia during pregnancy in Gondar, Northwest Ethiopia: an institutional based cross-sectional study. Anemia. 2014;2014:1-9.

33. Teruya SL, Gil HR, Teresi JA, Kong J, Eimicke J, Helmke S, Maurer MS. Facilitating clinical trials of anemia in older adults: a point-of-care system to measure hemoglobin in the home and its agreement with a hospital core laboratory. J Am Geriatr Soc. 2009;57(12):2362-4.

34. World Health Organization. Prevention and management of severe anaemia in pregnancy: report of a technical working group. Geneva: World Health Organization; 1991.

35. World Health Organization. Maternal anthropometry and pregnancy outcomes a who collaborative study. Geneva: World Health Organization; 1995.
36. Cogill B. Anthropometric indicators measurement guide series title II indicators guide. Revised edition. Food and nutrition technical assistance project (FANTA). 2003.

37. Obse N, Mossie A, Gobena T. Magnitude of anemia and associated risk factors among pregnant women attending antenatal care in Shalla Woreda, West Arsi Zone, Oromia Region, Ethiopia. Ethiop J Health Sci. 2013:23(2):165-73.

38. VanderJagt DJ, Brock HS, Melah GS, El-Nafaty AU, Crossey MJ, Glew RH. Nutritional factors associated with anaemia in pregnant women in northern Nigeria. J Health Popul Nutr. 2007;25(1):75-81.

39. Gies S, Brabin BJ, Yassin MA, Cuevas LE. Comparison of screening methods for anaemia in pregnant women in Awassa, Ethiopia. Trop Med Int Health. 2003;8(4):301-9.

40. Barooti E, Rezazadehkermani M, Sadeghirad B, Motaghipisheh S, Tayeri S, Arabi M, Salahi S, Haghdoost AA. Prevalence of iron deficiency anemia among Iranian pregnant women; a systematic review and meta-analysis. J Reprod Infertil. 2010;11(1):17-24.

41. Darnton-Hill I, Mkparu UC. Micronutrients in pregnancy in low-and middle-income countries. Nutrients. 2015;7(3):1744-68.

42. Bredesen JA. Women's use of healthcare services and their perspective on healthcare utilization during pregnancy and childbirth in a small village in northern India. Am Intern J Contemp Res. 2013:3(6):1-9.

43. Curtis Valerie, Cairncross Sandy, Yonli Raymond. Domestic hygiene and diarrhoea-pinpointing the problem. Trop Med Intern Health. 2000;5(1):22-32.

44. Marquis GS, Ventura G, Gilman RH, Porras E, Miranda EL, Carbajal L, Pentafiel M. Fecal contamination of shanty town toddlers in households with non-corralled poultry, Lima, Peru. Am J Public Health. 1990;80(2):146-9.

45. Mara D, Lane J, Scott B, Trouba D. Sanitation and health. PLoS Med. 2010;7(11):e1000363.

46. Stephenson LS, Holland C. The impact of helminth infections on human nutrition: schistosomes and soil-transmitted helminths. London: Taylor and Francis Ltd; 1987.

47. Stephenson LS, Latham MC, Ottesen EA. Malnutrition and parasitic helminth infections. Parasitology. 2000;121(S1):S23-38.

48. Smith JL, Brooker S. Impact of hookworm infection and deworming on anaemia in non-pregnant populations: a systematic review. Trop Med Int Health. 2010;15(7):776-95.

49. Brooker S, Hotez PJ, Bundy DA. Hookworm-related anaemia among pregnant women: a systematic review. PLoS Negl Trop Dis. 2008;2(9):e291.

50. Addis Alene K, Mohamed Dohe A. Prevalence of anemia and associated factors among pregnant women in an urban area of eastern Ethiopia. Anemia. 2014;2014:1-7.

51. Federal Ministry of Health. Protocol for the management of severe acute malnutrition. Addis Ababa: $\mathrm{FMOH} ; 2007$.

52. Hacker N, Moore J. Essentials of obstetrics and gynecology. 2nd ed. Pennsylvania:W.B. Saunders Company; 1992.

\section{Submit your next manuscript to BioMed Central and we will help you at every step:}

- We accept pre-submission inquiries

- Our selector tool helps you to find the most relevant journal

- We provide round the clock customer support

- Convenient online submission

- Thorough peer review

- Inclusion in PubMed and all major indexing services

- Maximum visibility for your research

Submit your manuscript at www.biomedcentral.com/submit
(OioMed Central 